\title{
Transformation of iron containing constituent intermetallic particles during hydrothermal treatment
}

\author{
Borgaonkar, Shruti; Din, Rameez Ud; Kasama, Takeshi; Ambat, Rajan
}

Published in:

Thin Solid Films

Link to article, DOI:

10.1016/j.tsf.2018.01.043

Publication date:

2018

Document Version

Peer reviewed version

Link back to DTU Orbit

Citation (APA):

Borgaonkar, S., Din, R. U., Kasama, T., \& Ambat, R. (2018). Transformation of iron containing constituent intermetallic particles during hydrothermal treatment. Thin Solid Films, 649, 121-128.

https://doi.org/10.1016/j.tsf.2018.01.043

\section{General rights}

Copyright and moral rights for the publications made accessible in the public portal are retained by the authors and/or other copyright owners and it is a condition of accessing publications that users recognise and abide by the legal requirements associated with these rights.

- Users may download and print one copy of any publication from the public portal for the purpose of private study or research.

- You may not further distribute the material or use it for any profit-making activity or commercial gain

- You may freely distribute the URL identifying the publication in the public portal

If you believe that this document breaches copyright please contact us providing details, and we will remove access to the work immediately and investigate your claim. 


\title{
Transformation of iron containing constituent intermetallic particles during hydrothermal treatment
}

\author{
Shruti Borgaonkar ${ }^{\mathrm{a}}$, Rameez Ud Din ${ }^{1, \mathrm{a}}$, Takeshi Kasama ${ }^{\mathrm{b}}$, Rajan Ambat ${ }^{\mathrm{a}}$ \\ a. Section of Materials and Surface Engineering, Department of Mechanical Engineering, \\ Produktionstorvet, Technical University of Denmark, Kongens Lyngby 2800, Denmark \\ b. Center for Electron Nanoscopy, Fysikvej, Technical University of Denmark, Kongens Lyngby 2800, \\ Denmark
}

\section{Abstract}

Aluminium alloys AA3102 and AA9108 were treated with high temperature steam, which resulted in the formation of an oxide layer of average thickness of 300-400 nm. Hydrothermal steam treatment resulted in the removal or oxidation of $\mathrm{Al}(\mathrm{Fe}) \mathrm{Mn}$ and $\mathrm{Al}(\mathrm{Fe}-\mathrm{Si}) \mathrm{Mn}$ type intermetallic particles present in the alloys. Furthermore, electron energy loss spectroscopy analysis revealed that the during the steam treatment, the Fe enriched areas of the $\mathrm{Al}(\mathrm{Fe}-\mathrm{Si}) \mathrm{Mn}$ type intermetallic particles were transformed into $\mathrm{Fe}_{2} \mathrm{O}_{3}$ and $\mathrm{Fe}_{3} \mathrm{O}_{4}$ phases, while energy-dispersive X-ray spectroscopy line profile measurements by scanning transmission electron microscope showed that $\mathrm{Mn}$ and Si were leached out and incorporated into the surrounding oxide layer. Further, the part of intermetallic phase was transformed into polycrystalline material.

Keywords: Steam; Aluminium alloys; Intermetallic particles; Transmission electron microscopy; Electron energy loss spectroscopy

${ }^{1}$ Corresponding author e-mail: rudin@mek.dtu.dk, Tel : +45 45254715 Fax : +45 45936213 


\section{Introduction}

Aluminium and its alloys are widely used in the aerospace, architectural, and automotive industries due to its light weight, good mechanical properties, corrosion resistance, and recyclability [13]. During the manufacturing process, elemental additives are added to increase the mechanical properties of the aluminium alloys [4-7]. However, the amounts of iron, silicon, and manganese play an important role in establishing the mechanical properties of the aluminium alloys [8]. Iron as an impurity, is always present in the alloys made from commercially pure base material. The solid solubility of iron in aluminium is very low with the result that most iron present leads to the formation of the intermetallic compounds. The chemical composition of such intermetallic phases strongly depends on other impurities or alloying elements present in the alloy system [9]. Further, Manganese is the most common alloying addition, which is used to neutralize the effect of iron by preventing the formation of $\mathrm{FeAl}_{3}$ or $\mathrm{FeSi}$ rich phases [10]. In most manganese based aluminium alloys, iron can replace large amounts of manganese in the intermetallics without changing the crystalline structure i.e. $(\mathrm{FeMn}) \mathrm{Al}_{6}$ and $(\mathrm{FeMn})_{3} \mathrm{Si}_{2} \mathrm{Al}_{15}[8,9]$. Furthermore, in the Si based the alloy systems, mainly $\mathrm{FeSiAl}_{5}$ intermetallic compound is usually present, while number of others have reported the formation of AlFe-Si type intermetallics [11-13]. However, the replacement of $\mathrm{FeSiAl}_{5}$ phase by manganese based intermetallic compounds is of great interest due to the corrosion resistance properties. It is reported that manganese addition to the intermetallics reduces the potential difference between the iron-bearing intermetallic particles and the matrix $[10,14]$.

In general, the presence of these intermetallic particles in aluminium matrix results in the heterogeneous microstructure, which has a high impact on the corrosion resistance properties of aluminium alloys [15-19]. Thus, aluminium alloys essentially require pre-treatment (well known as 
conversion coatings) to maintain its corrosion performance with or without polymer coatings such as paints [20-26]. However, the formation of various conversion coatings on commercial aluminium alloys such as AA3000, AA2000 and AA7000 series is complicated due to the presence of variety of intermetallic particles [27-32]. For instance, the formation of chromate conversion coating on $\mathrm{Cu}$ enriched intermetallic particles resulted in the formation of thinner oxide layer over the copper rich particles when compared to the aluminium matrix [28]. Further, no $\mathrm{Cr}$ (III)-Cr (VI) mixed oxides over $\mathrm{AlCuMg}, \mathrm{Al}_{2} \mathrm{CuMg}$, and $\mathrm{Al}_{5} \mathrm{CuMg}_{4}$, which is usually present over aluminium matrix, were observed, while thicker films were observed on $\mathrm{Al}_{8} \mathrm{Mg}$ intermetallic particles [33,34]. Cerium based conversion coatings is one of the most promising chromate free pre-treatment which have been studied extensively [35]. A number of investigations [36,37] revealed that the preferential precipitation of the Ce oxide layer occurs at the top of $\mathrm{Cu}$-containing intermetallic particles, which was due to the cathodic nature of these intermetallic particles. However, the $\mathrm{Cu}$ free cathodic intermetallic particles i.e. $(\mathrm{Fe}, \mathrm{Cr})_{3} \mathrm{SiAl}_{12}$, $\mathrm{FeNiAl}_{9}, \mathrm{Al}_{6}-(\mathrm{Mn}, \mathrm{Fe}, \mathrm{Cr})$ did not exhibit the rapid deposition of cerium oxide layer [27,36-39]. Similarly, permanganate conversion coatings appear to have some promising properties as on aluminium alloys [40-42]. During the formation of permanganate conversion coating on AA2024, the deposition of $\mathrm{MnO}_{2}$ oxide layer was observed over cathodic intermetallic particles, which was considerably thicker than on the aluminium matrix [43]. Thus, it is evident that the composition and chemical nature of intermetallic particles significantly influence the formation of various conversion coating, which in general influences the corrosion performance of aluminium alloys $[27,31,34,44-46]$.

A number of studies [47-53] have been reported on the hydrothermal treatment of aluminium alloys, which results in the formation of aluminium hydroxide layer. However, these studies do not deal with the fundamental role of intermetallic particles in the growth and corrosion resistance properties of hydrothermally grown films. Our earlier work [54-57] of hydrothermal treatment of aluminium alloys 
with steam showed that the growth of aluminium hydroxide was thicker on Al-Fe-Si intermetallic particles when compared to the aluminium matrix and resulted in the partial oxidation of the intermetallic phases. Further, in the presence of acidic chemistries, the intermetallic particles were the preferential sites for initiation of oxide growth [56]. However, these studies do not deal with the change in the microstructure of specific types of intermetallic particles before and after the steam treatment. The later investigations showed that the presence of oxide at the intermetallic may significantly affect the adhesion performance of the commercially applied powder coating [58]. Thus, the purpose of present study is to investigate chemical and microstructure changes to the intermetallic particles under hydrothermal conditions. Therefore, the growth of the aluminium hydroxide films on AA3102 and AA9108 was investigated; where the effect of steam treatment on $\mathrm{Al}(\mathrm{Fe}) \mathrm{Mn}$ and $\mathrm{Al}(\mathrm{Fe}-\mathrm{Si}) \mathrm{Mn}$ type of intermetallic particles were studied in detail. The detailed microstructural characterization of the produced coatings has been carried out using glow discharge optical emission spectroscopy (GD-OES) and, scanning electron microscopy (SEM) and transmission electron microscopy (TEM) including energy dispersive X-ray spectroscopy (EDS) and electron energy loss spectroscopy (EELS).

\section{Experimental methods}

\subsection{Material}

Commercial aluminium alloys AA3102 and AA9108 were used as the substrate for the investigations. Chemical composition of the alloys in as-received condition is shown in Table 1. Prior to the hydrothermal surface treatment, the samples were cut into $20 \mathrm{~mm} \times 15 \mathrm{~mm}$ test coupons and ultrasonically cleaned for $5 \mathrm{~min}$, by using analytical grade acetone as a solvent. After being cleaned in acetone, they were rinsed in deionised water and dried using an air gun. 


\subsection{Sample preparation}

In order to identify various intermetallic particles and to locate the analysis area before and after the steam treatment, a set of micro-hardness indents were made using a Vickers micro hardness indentor (FutureTech FM 700 micrhardness tester) with a load of 50g. Using these indentation marks, the same intermetallics particles could be analysed before and after the hydrothermal steam treatment. Prior to the steam treatment, the samples were degreased for 1 min in 5 wt. \% commercial Alficlean (weakly alkaline detergent $\mathrm{pH}=7.5-8$ ) aqueous solution at $30{ }^{\circ} \mathrm{C}$ followed by rinsing in distilled water and dried in ambient air.

\subsection{Steam treatment}

The samples were exposed to high temperature steam, generated from deionised water in an autoclave (All American Pressure Canners, USA) at $107^{\circ} \mathrm{C}$ and $130 \mathrm{kPa}$ vapour pressure, for a period of 30,60, 120, 240 and 600 seconds, respectively. After the steam treatment, the samples were rinsed with deionised water and dried in ambient air.

\subsection{Microstructural characterization}

\subsubsection{Glow discharge optical emission spectroscopy (GD-OES)}

After the steam treatment, the thickness and relative chemical composition of the surface layers were analysed using GD-OES (GD-2 profiler, Horiba Jobin YVON). The instrument is equipped with a radio frequency generator, a standard discharge source with an anode of $4 \mathrm{~mm}$ internal diameter, a monochromator and polychromator optical spectrometers, and Quantum XP software. Calibration of the GD-OES profiler was carried out at optimised discharge condition of $850 \mathrm{~Pa}$ pressure and RF power of $40 \mathrm{~W}$ by sputtering the sample surface for a specific time and then measuring the depth of the resulting sputtered crater using a surface profilometer. 


\subsubsection{Scanning electron microscopy (SEM)}

The morphology and composition of intermetallic particles present at the surfaces of aluminium alloy before and after the steam treatment were investigated using field emission gun (FEG) SEM (Quanta 200 FEG MKII, FEI) with an Oxford Instrument INCA EDS analyser. The EDS analysis has been performed with an acceleration voltage of $15 \mathrm{keV}$ and $\mathrm{Cu}$ calibration.

\subsubsection{Transmission electron microscopy (TEM), Electron energy loss (EELS) and energy dispersive X-ray (EDS) spectroscopies}

Thin film lamella from the steam treated surfaces were prepared using in-situ lift-out technique using a dual beam focused ion beam SEM (FIB-SEM) (Quanta 200 3D DualBeam, FEI) and were further thinned down to approximately $120 \mathrm{~nm}$ thickness for electron transparency in a FIB-SEM (Helios Nanolab DualBeam, FEI). A FEI Tecnai G2 T20 TEM was used at $200 \mathrm{keV}$ to investigate the prepared lamellae. The EELS spectra were acquired with a dispersion of $0.05 \mathrm{eV} / \mathrm{channel}$ and an energy resolution of $1 \mathrm{eV}$ in TEM diffraction mode. The EELS spectra were processed using Digital Micrograph software from Gatan. EDS was performed at $200 \mathrm{kV}$ using the Tecnai TEM equipped with an Oxford Instruments X-MaxN 80 T silicon drift detector. The EDS spectra were processed using TIA software from FEI Company. 


\section{Results and Discussion}

\subsection{Microstructural characterization}

\subsubsection{Glow discharge optical emission spectroscopy (GD-OES) analysis}

Figure 1 shows a typical GD-OES depth profile and an average oxide thickness on AA3102 and AA9108 after steam treatment for 30, 60, 120, 240, and 600 seconds. The X-axis in Figure 1(a) shows the sputter time converted into sputter depth using regulated sputter rate vs. depth data for aluminium oxide and aluminium substrate. This data was obtained by calibrating sputter depth of the craters using GD-OES for a specific time. The average sputter rates for the steam generated oxide and aluminium substrate at a given pressure $(850 \mathrm{~Pa})$ and RF power $(40 \mathrm{~W})$ were $30 \mathrm{~nm} / \mathrm{s}$ and $65 \mathrm{~nm} / \mathrm{s}$ respectively. The concentration of elements shown by the GD-OES profile were relatively compared, a decrease in the intensity of oxygen $(\mathrm{O})$ counts is related to an increase in the intensity of aluminium, indicating the interface between the steam generated oxide layer and the aluminium substrate as presented in Figure 1(a). Although not shown here, a similar GD-OES profile was obtained for steam treated AA3102 surface except for the slight shift in the position of various interfaces, which is summarized for both alloys in Figure 1(b). In general, the average thickness of the oxide film generated by steam treatment on the AA9108 surface was higher by about $100 \mathrm{~nm}$ than that on the AA3102 surface after $600 \mathrm{~s}$. The initial growth of the oxide on both alloys was similar up to $120 \mathrm{~s}$, while with an increase in the process time, slight increase in the thickness of oxide was evident for AA9108. Overall, the results indicated that the thickness of the oxide layer was also a function of the type of alloy, after $600 \mathrm{~s}$ of steam treatment. Further, the thickness of oxide was slightly lower than the reported data where relatively pure aluminium alloys were treated under similar conditions [54,59]. Moreover, previous studies [54] reported that the thickness of oxide layer was a function of steam vapour pressure although the growth 
rate of oxide as a function of steam treatment time at $130 \mathrm{kPa}$ pressure was less pronounced, which is in agreement with the data reported in the present study. The increase in the content of Si at the surface is reported to inhibit the formation of aluminium hydroxide $[53,60]$.This can explain the lower thickness of the oxide on AA3102 where amount of Si was two times higher than AA9108. Further, the presence of $\mathrm{Mg}$ at the aluminium surface may induce this phenomenon, where higher levels of $\mathrm{Mg}$ is reported to facilitate kinetics of the reaction as well as oxide thickness [48].

\subsubsection{Surface morphology before and after steam treatment}

Figure 2 (a) and (b) show the AA3102 and AA9108 surfaces prior to the steam treatment. The surface of both alloys showed the presence of rolling streaks and bright intermetallic particles. The size of the bright intermetallic particles varied from $0.3 \mu \mathrm{m}$ up to $10 \mu \mathrm{m}$. The EDS analysis (not shown here) of the intermetallic particles of size between 1-10 $\mu$ m showed the presence $\mathrm{Al}, \mathrm{Fe}, \mathrm{Mn}$, and $\mathrm{Si}$ corresponding to an $\mathrm{Al}(\mathrm{Fe}) \mathrm{Mn}$ and $\mathrm{Al}(\mathrm{Fe}-\mathrm{Si}) \mathrm{Mn}$ type intermetallic particles.

Figure 2I and (d) show the typical coverage of the AA3102 and AA9108 alloy surfaces after steam treatment. It is evident that the steam treatment resulted in the formation of dark areas in the SEM micrograph where the contrast difference indicates the formation of a lighter material with either a lower mean atomic number or lower density. Further, the dark areas were concentrated around the intermetallic particles. The EDS analysis (presented in Table 2) of the aluminium matrix and the intermetallic particles showed the presence of significant amount of oxygen suggesting the formation of an oxide layer over the entire aluminium alloy surface. Further, the EDS measurements from the intermetallic particles might contain signals from the substrate where the interaction volume is 
normally $3 \times 3 \times 3 \mu \mathrm{m}$ for light materials at $20 \mathrm{keV}$. Although not shown here, the short steam treatment times also resulted in the similar coverage oxide layer on the surface.

In order to identify the behaviour of $\mathrm{Al}(\mathrm{Fe}) \mathrm{Mn}$ and $\mathrm{Al}(\mathrm{Fe}-\mathrm{Si}) \mathrm{Mn}$ type intermetallic particles under hydrothermal treatment conditions, certain areas of the alloy surfaces were marked using microhardness indentations and analysed under SEM, before and after the steam treatment as presented in Figure 3 (marked by arrows). The results indicated that the steam treatment resulted in the removal of some of the large intermetallic particles (marked by circle in Figure 3 (a) and Figure 3 (c)), whereas the rest of intermetallic particles were entrapped in the oxide layer and appeared as circular regions. However, in some circular regions no intermetallic particle was detected. Further, the EDS analysis (presented in the Table 3) of these intermetallic particles also showed the presence of Si and Mn in the oxide layer present close to the edge of the circular regions.

Figure 4 shows the secondary electron SEM images that represent the surface morphology of steam treated AA3102 and AA9108 aluminium alloys. In general, both surfaces after the steam treatment showed the presence of needle-like structure, which was homogenously covering the aluminium matrix (Figure 4 (a) and Figure 4 (d)) and intermetallic particles ((Figure 4 (b) and Figure 4 I)). However, the growth of the oxide appeared to be higher around the intermetallic particles. The FIB cross section images (Figure 4 (c) and Figure 4 (f)) of these intermetallic particles revealed that the particles were covered with an oxide layer having needle structured oxide at the top and compact oxide at the bottom. Further, in some areas intermetallic particles were not observed, which suggested that the intermetallic particle had been dissolved/dislodged during the steam treatment. Additionally, the growth of the compact oxide beneath the intermetallic particles was 5-6 times higher than at the top, 
which led to the entrapment of intermetallic particles into oxide layer. This will electrochemically isolate them from the aluminium matrix.

The typical growth mechanism of oxide layer under steam conditions is governed by the hydration of the aluminium surface [51], where the formation of the layer takes place due to electrochemical process occurring at the aluminium metal surface. During this electrochemical process, the anodic and cathodic half reactions can be summarised as presented in equation 1 and equation 2.

$$
\begin{aligned}
& \mathrm{Al}+2 \mathrm{H}_{2} \mathrm{O} \longrightarrow \mathrm{AlOOH}+3 \mathrm{H}^{+}+3 \mathrm{e}^{-} \\
& 3 \mathrm{H}_{2} \mathrm{O}+3 \mathrm{e}^{-} \longrightarrow 1.5 \mathrm{H}_{2}+3 \mathrm{OH}^{-}
\end{aligned}
$$

During this process the anodic reaction takes place all over the surface whereas the cathodic reaction takes place at the intermetallic particles [61]. In the early stages of the reaction, the dissolution of aluminium was accompanied by the simultaneous precipitation of hydroxide film that can be transformed into aluminium hydroxide. After initial formation of hydroxide, the growth mechanism of these films shifts towards the solid-state diffusion of water, through the already present oxide layer. Under such conditions, the formation of new film takes place beneath the existing film $[50,61,62]$. The formation of thicker oxide layer around the intermetallic particles was greater, which can be attributed to the localised potential difference provided by the cathodic nature of the iron enriched intermetallic particles $[16,63,64]$. This potential difference resulted in the formation of micro-galvanic couples that led to the localized attack near the particles promoting rapid anodic dissolution of aluminium and formation of a cavity around the particles, which was reported under steam conditions [55]. 


\subsubsection{Transmission electron microscopy}

Figure 5 shows the bright field transmission electron micrographs of the cross sections of the aluminium matrix and intermetallic particles after the steam treatment. In general, the cross sections showed clearly distinguishable layers; namely, a layer with needle structure, a compact layer at the bottom as presented in Figure 5 (a) and Figure 5 (b). The compact layer was close to the aluminium substrate interface and contained no porosity. Further, the intermetallic particle was completely embedded into the oxide layer with needle structure. However, the intermetallic particle clearly showed the presence of two distinct areas namely; "core" marked as (1) and "rim" marked as (2) in Figure 5 (b).

The diffraction patterns and dark-field images obtained from these regions indicated that the core was composed of an amorphous-like phase coexisting with a small amount of a crystalline phase, while the rim showed the crystalline nature with preferential crystal orientations, as shown in Figure 6 (a). The crystals of the rim have $<10 \mathrm{~nm}$ in size and appear to be embedded in the amorphous-like phase. The crystallinity and crystal size changes may occur by the oriented attachment mechanism, which is occasionally observed in the crystal growth of iron oxides/hydroxides [65-67]. Several number of diffraction patterns acquired from different regions showed the similarity among them. The contrast variation between the regions 1 and 2 in the bright-field images would be originated from the crystal size and crystallinity differences (i.e. diffraction contrast).

Further, in order to identify the elemental composition of the intermetallic particle an EDS line scan from points A to B (marked in Figure 5 (b)) was performed and presented in Figure 6 (b). Overall, the line scan showed the presence of $\mathrm{O}, \mathrm{Al}, \mathrm{Si}, \mathrm{Mn}$, and Fe from both the "core" and "rim" regions, suggesting the oxidised Al-Fe-Si phase. Furthermore, the outside area of the intermetallic particle, 
showed mainly the presence of $\mathrm{Al}, \mathrm{O}$ while low intensities of $\mathrm{Mn}$, and $\mathrm{Si}$ was noticeable. In general, the results clearly showed that the steam treatment resulted in the oxidation of intermetallic particle while some of the elements from the intermetallic particles leached out and incorporated into the surrounding oxide.

The results of the present work clearly show that the Fe-containing particles i.e. Al-Fe-Si phase incorporated into the steam generated oxide film because of the cathodic nature of these intermetallic particles as discussed in the section 3.1.2, which caused the rapid anodic dissolution of aluminium and formation of a cavity around the particles. Further, the acidification of $\mathrm{pH}$ inside the cavity because of the hydrolysis may lead to the partial dissolution or de-alloying of the intermetallic particles because of selective leaching of aluminium or other active elements [60,68]. The high temperature of steam produced rapid oxidation of the leached elements, ultimately incorporating these elements into the edge of the oxide present at the intermetallic particles $[55,56]$. Furthermore, the incorporation and partial oxidation of Fe enriched particles into anodic oxide film have been reported by many researchers [69$71]$ in the anodising process, which was in an agreement with the oxidation of intermetallic particles by steam treatment $[54-56]$.

\subsubsection{Electron energy loss spectroscopy (EELS)}

The line scan results showed that the intermetallic particle was oxidised, therefore, EELS studies were carried out on region 1 and region 2 as marked on Figure 5 (b) and EELS spectra of iron and oxygen edge is presented in Figure 7. In general, it is difficult to distinguish between the various iron oxide phases using only the iron edge spectrum, therefore more information can be generated by the oxygen edge, which also gives information on the oxidation state of iron and the iron oxide phase to 
which the oxygen atoms belong [72,73]. Some characteristic features from the EELS measurements of regions 1 and 2 are as follows:

(i) The pre-peak below $530 \mathrm{eV}$ is clearly visible in most of iron oxides/hydroxides except for $\mathrm{FeO}$, suggesting that the both regions do not contain FeO.

(ii) A weak peak at 540-550 eV for which position and shape vary between different compounds is exhibited in $\mathrm{Fe}_{3} \mathrm{O}_{4}$ and gamma- $\mathrm{Fe}_{2} \mathrm{O}_{3}$ and less pronounced in alpha- $\mathrm{Fe}_{2} \mathrm{O}_{3}$ and $\mathrm{FeO}$. The oxygen $K$ edge spectrum from the region 2 shows a distinctive peak at $543 \mathrm{eV}$.

(iii) The intensity ratios of $\mathrm{Fe} L_{3} / \mathrm{Fe} L_{2}$ ( 8.2 for region 1 and $\sim 9.4$ for region 2 ), which were calculated according to literature [67], which suggest that the iron oxidation states in the both regions would be mostly $\mathrm{Fe}^{3+}$.

Thus, the region 2 is most likely to be composed of gamma- $\mathrm{Fe}_{2} \mathrm{O}_{3}$ along with the amorphous-like material that is filled in between the gamma-Fe ${ }_{2} \mathrm{O}_{3}$ crystalline phase. The diffraction pattern of the region 2 also supports the formation of gamma- $\mathrm{Fe}_{2} \mathrm{O}_{3}$. The region 1 consists mainly of an amorphouslike phase, which has some similarity to gamma- $\mathrm{Fe}_{2} \mathrm{O}_{3}$ and $\mathrm{Fe}_{2} \mathrm{O}_{3}$ in its local structure. Our EELS measurements show no clear evidence of formation of metallic $\mathrm{Fe}, \mathrm{FeO}$ or $\mathrm{Fe}_{3} \mathrm{O}_{4}$.

Moreover, in the present analysis, the identification of iron oxide was carried out by the analysis of oxygen edge spectra which provides better information on the oxidation state instead of only iron edge spectra as reported by others in literature [72,74]. Further, there was no prior EELS study was reported in literature on the microstructural changes of intermetallic particles after steam treatment. However, study related to the oxidation of intermetallic particles after anodising was reported in literature [75]. Where, the EELS study of anodic films developed on aluminium chromium alloy were 
characterised morphologically by transmission electron microscopy, with precise composition, and valence states of relevant species determined by EELS analysis and other nano-scale techniques [75].

Overall EELS analysis of intermetallic particle oxidation after steam treatment provides fundamental understanding about the conversion coating performance under the polymer-coated specimen, where formation of mix oxide plays a vital role in the adhesion mechanism as well as overall performance of the conversion coating during service.

\section{Conclusions}

The steam treatment of aluminium alloys resulted in the cleaning of the aluminium alloy surface by the removal or oxidation of $\mathrm{Al}(\mathrm{Fe}) \mathrm{Mn}$ and $\mathrm{Al}(\mathrm{Fe}-\mathrm{Si}) \mathrm{Mn}$ type intermetallic particles. Furthermore, the steam treatment also formed an oxide layer on AA3102 and AA9108 surface while the thickness of the oxide was dependent on the presence of various elements in the alloy i.e. $\mathrm{Fe}, \mathrm{Si}$ and $\mathrm{Mn}$. The elemental compositional profile across the intermetallic particles showed that after steam treatment certain elements leached from the intermetallic particles i.e. Si and $\mathrm{Mn}$, and incorporated in the surrounding oxide layer. Moreover, the EELS analysis of the oxide present at Al-Fe-Mn-Si intermetallic particle after steam treatment showed formation of gamma- $\mathrm{Fe}_{2} \mathrm{O}_{3}$ and $\mathrm{Fe}_{2} \mathrm{O}_{3}$ phases.

\section{Acknowledgements}

The authors would like to thank the Danish National Advanced Technology Foundation for the financial support under the project titled Steam Initiated Surface Technology (SIST) and all the 
involved project partners. The A. P. Møller and Chastine Mc-Kinney Møller Foundation is gratefully acknowledged for their contribution toward the establishment of the Center for Electron Nanoscopy in the Technical University of Denmark. 


\section{$5 \quad$ References}

[1] A. Heinz, A. Haszler, C. Keidel, S. Moldenhauer, R. Benedictus, W.S. Miller, Recent development in aluminium alloys for aerospace applications, Mater. Sci. Eng. A. 280 (2000) 102-107. doi:10.1016/S0921-5093(99)00674-7.

[2] W.S. Miller, L. Zhuang, J. Bottema, A.J. Wittebrood, P. De Smet, A. Haszler, A. Vieregge, Recent development in aluminium alloys for the automotive industry, Mater. Sci. Eng. A. 280 (2000) 37-49.

[3] J.C. Williams, E.A. Starke Jr., Progress in structural materials for aerospace systems, Acta Mater. 51 (2003) 5775-5799. doi:10.1016/j.actamat.2003.08.023.

[4] M. Warmuzek, W. Ratuszek, G. Sęk-Sas, Chemical inhomogeneity of intermetallic phases precipitates formed during solidification of Al-Si alloys, Mater. Charact. 54 (2005) 31-40.

[5] N.A. Belov, D.G. Eskin, A.A. Aksenov, Multicomponent phase diagrams: applications for commercial aluminum alloys, Elsevier, 2005.

[6] M. Warmuzek, G. Mrówka, J. Sieniawski, Influence of the heat treatment on the precipitation of the intermetallic phases in commercial AlMn1FeSi alloy, J. Mater. Process. Technol. 157-158 (2004) 624-632. doi:10.1016/j.jmatprotec.2004.07.125.

[7] S. Ji, W. Yang, F. Gao, D. Watson, Z. Fan, Effect of iron on the microstructure and mechanical property of Al-Mg-Si-Mn and Al-Mg-Si diecast alloys, Mater. Sci. Eng. A. 564 (2013) 130-139. doi:10.1016/j.msea.2012.11.095.

[8] J.E. Hatch, Aluminum: properties and physical metallurgy, ASM International, 1984.

[9] N.A. Belov, A.A. Aksenov, D.G. Eskin, Iron in aluminium alloys: impurity and alloying element, CRC Press, 2002.

[10] L.F. Mondolfo, Aluminum alloys: structure and properties, Elsevier, 2013.

[11] S. Yaneva, N. Stoichev, Z. Kamenova, S. Budurov, Quaternary iron-containing phases in al-si cast alloys., Zeitschrift Fuer Met. Res. Adv. Tech. 75 (1984) 395-398.

[12] J.G. Barlock, L.F. Mondolfo, Structure of some aluminium-iron-magnesium-manganese-silicon alloys., Zeitschrift Fuer Met. Res. Adv. Tech. 66 (1975) 605-611.

[13] A.L. Dons, AlFeSi-particles in commercial pure aluminium., Zeitschrift Fuer Met. Res. Adv. Tech. 75 (1984) 170-174. 
[14] S.G. Shabestari, The effect of iron and manganese on the formation of intermetallic compounds in aluminum-silicon alloys, Mater. Sci. Eng. A. 383 (2004) 289-298.

doi:10.1016/j.msea.2004.06.022.

[15] R. Ambat, A.J. Davenport, G.M. Scamans, A. Afseth, Effect of iron-containing intermetallic particles on the corrosion behaviour of aluminium, Corros. Sci. 48 (2006) 3455-3471. doi:10.1016/j.corsci.2006.01.005.

[16] K. Nis, Electrochemical Behavior of Aluminum-Base Intermetallics Containing Iron, J. Electrochem. Soc. 137 (1990) 69-77.

[17] G.O. Ilevbare, O. Schneider, R.G. Kelly, J.R. Scully, In situ confocal laser scanning microscopy of AA 2024-T3 corrosion metrology I. Localized corrosion of particles, J. Electrochem. Soc. 151 (2004) B453-B464.

[18] A. Davoodi, J. Pan, C. Leygraf, R. Parvizi, S. Norgren, An insight into the influence of morphological and compositional heterogeneity of an individual intermetallic particle on aluminium alloy corrosion initiation, Mater. Corros. 64 (2013) 195-198.

[19] A. Davoodi, J. Pan, C. Leygraf, S. Norgren, The role of intermetallic particles in localized corrosion of an aluminum alloy studied by SKPFM and integrated AFM/SECM, J. Electrochem. Soc. 155 (2008) C211-C218.

[20] P. Campestrini, H. Terryn, J. Vereecken, J.H.W. De Wit, Chromate conversion coating on aluminum alloys II: Effect of the microstructure, J. Electrochem. Soc. 151 (2004) B359-B369. doi:10.1149/1.1736682.

[21] J. V Kloet, W. Schmidt, A.W. Hassel, M. Stratmann, The role of chromate in filiform corrosion inhibition, Electrochim. Acta. 48 (2003) 1211-1222. doi:10.1016/S0013-4686(02)00829-0.

[22] M.F. Abd Rabbo, J.A. Richardson, G.C. Wood, A study of conversion coating development on aluminium in chromate/fluoride solutions using secondary ion mass spectrometry, Corros. Sci. 18 (1978) 117-123. doi:10.1016/S0010-938X(78)80082-1.

[23] D. Chidambaram, C.R. Clayton, G.P. Halada, The role of hexafluorozirconate in the formation of chromate conversion coatings on aluminum alloys, Electrochim. Acta. 51 (2006) 2862-2871. doi:10.1016/j.electacta.2005.08.022.

[24] O. Lunder, B. Olsen, K. Nisancioglu, Pre-treatment of AA6060 aluminium alloy for adhesive bonding, Int. J. Adhes. Adhes. 22 (2002) 143-150.

[25] O. Lunder, B. Olsen, K. Nisancioglu, Pre-treatment of AA6060 aluminium alloy for adhesive bonding, Int. J. Adhes. Adhes. 22 (2002) 143-150. doi:10.1016/S0143-7496(01)00049-5. 
[26] O. Lunder, F. Lapique, B. Johnsen, K. Nisancioglu, Effect of pre-treatment on the durability of epoxy-bonded AA6060 aluminium joints, Int. J. Adhes. Adhes. 24 (2004) 107-117. doi:10.1016/j.ijadhadh.2003.07.002.

[27] P. Campestrini, H. Terryn, A. Hovestad, J.H.W. de Wit, Formation of a cerium-based conversion coating on AA2024: Relationship with the microstructure, Surf. Coatings Technol. 176 (2004) $365-381$.

[28] H. Piao, N.S. McIntyre, On the nature of the chromate conversion coating formed on intermetallic constituents of AA2024-T3, Surf. Interface Anal. 33 (2002) 607-616. doi:10.1002/sia.1428.

[29] A.S. Hamdy, I. Doench, H. Möhwald, Intelligent self-healing corrosion resistant vanadia coating for AA2024, Thin Solid Films. 520 (2011) 1668-1678. doi:10.1016/j.tsf.2011.05.080.

[30] D. Chidambaram, M.J. Vasquez, G.P. Halada, C.R. Clayton, Studies on the repassivation behavior of aluminum and aluminum alloy exposed to chromate solutions, Surf. Interface Anal. 35 (2003) 226-230. doi:10.1002/sia.1507.

[31] Y. Guo, G.S. Frankel, Characterization of trivalent chromium process coating on AA2024-T3, Surf. Coatings Technol. 206 (2012) 3895-3902.

[32] Q. Meng, G.S. Frankel, Characterization of chromate conversion coating on AA7075-T6 aluminum alloy, Surf. Interface Anal. 36 (2004) 30-42.

[33] W.R. McGovern, P. Schmutz, R.G. Buchheit, R.L. McCreery, Formation of Chromate Conversion Coatings on Al-Cu-Mg Intermetallic Compounds and Alloys, J. Electrochem. Soc. 147 (2000) 4494-4501.

[34] S. a. Kulinich, a. S. Akhtar, D. Susac, P.C. Wong, K.C. Wong, K. a. R. Mitchell, On the growth of conversion chromate coatings on 2024-Al alloy, Appl. Surf. Sci. 253 (2007) 3144-3153. doi:10.1016/j.apsusc.2006.07.004.

[35] M. Bethencourt, F.J. Botana, J.J. Calvino, M. Marcos, M.A. Rodríguez-Chacón, Lanthanide compounds as environmentally-friendly corrosion inhibitors of aluminium alloys: A review, Corros. Sci. 40 (1998) 1803-1819.

[36] A.E. Hughes, J.D. Gorman, P.J.K. Paterson, The characterisation of Ce-Mo-based conversion coatings on Al-alloys: Part I, Corros. Sci. 38 (1996) 1957-1976. doi:10.1016/S0010938X(96)00088-1.

[37] A.J.J. Aldykewicz, H.S. Isaacs, A.J. Davenport, Investigation of cerium as a cathodic inhibitor for aluminum-copper alloys, J. Electrochem. Soc. 142 (1995) 3342-3350. 
[38] L. Armelao, M. Dabalà, I. Calliari, A. Buchberger, Cerium-based conversion layers on aluminum alloys, Appl. Surf. Sci. 172 (2001) 312-322. doi:10.1016/S0169-4332(00)00873-4.

[39] M.A. Arenas, M. Bethencourt, F.J. Botana, J. de Damborenea, M. Marcos, Inhibition of 5083 aluminium alloy and galvanised steel by lanthanide salts, Corros. Sci. 43 (2001) 157-170.

[40] S. a. Kulinich, a. S. Akhtar, On conversion coating treatments to replace chromating for $\mathrm{Al}$ alloys: Recent developments and possible future directions, Russ. J. Non-Ferrous Met. 53 (2012) 176-203. doi:10.3103/S1067821212020071.

[41] J.W. Bibber, Corrosion resistant aluminum coating composition, US Patent US4755224, Nov. 7, 1989.

[42] J.W. Bibber, Corrosion resistant aluminum coating composition, US Patent 4878963, Jul. 5, 1988.

[43] S.A. Kulinich, A.S. Akhtar, P.C. Wong, K.C. Wong, K.A.R. Mitchell, Growth of permanganate conversion coating on 2024-Al alloy, Thin Solid Films. 515 (2007) 8386-8392.

[44] O. Lunder, J.C. Walmsley, P. Mack, K. Nisancioglu, Formation and characterisation of a chromate conversion coating on AA6060 aluminium, Corros. Sci. 47 (2005) 1604-1624. doi:10.1016/j.corsci.2004.08.012.

[45] J.. Nordlien, J.. Walmsley, H. Østerberg, K. Nisancioglu, Formation of a zirconium-titanium based conversion layer on AA 6060 aluminium, Surf. Coatings Technol. 153 (2002) 72-78. doi:10.1016/S0257-8972(01)01663-2.

[46] G.M. Brown, K. Kobayashi, Nucleation and Growth of a Chromate Conversion Coating on Aluminum Alloy AA 2024-T3, J. Electrochem. Soc. 148 (2001) B457-B466. doi:10.1149/1.1409544.

[47] J.D. Gorman, A.E. Hughes, D. Jamieson, P.K.J. Paterson, Oxide formation on aluminum alloys in boiling deionised water and $\mathrm{NaCl}, \mathrm{CeCl} 3$ and $\mathrm{CrCl} 3$ solutions, Corros. Sci. 45 (2003) 11031124. doi:10.1016/S0010-938X(02)00209-3.

[48] A. Strålin, T. Hjertberg, Influence of surface composition on initial hydration of aluminium in boiling water, Appl. Surf. Sci. 74 (1994) 263-275.

[49] R.S. Alwitt, Hydrous aluminum oxide films in electrolytic capacitors, J. Electrochem. Soc. 3 (1973) 120.

[50] R.K. Hart, The formation of films on aluminium immersed in water, Trans. Faraday Soc. 53 (1957) 1020-1027. 
[51] R.S. Alwitt, The growth of hydrous oxide films on aluminum, J. Electrochem. Soc. 121 (1974) $1322-1328$.

[52] H. Uchi, T. Kanno, R.S. Alwitt, Structural features of crystalline anodic alumina films, J. Electrochem. Soc. 148 (2001) B17-B23. doi:10.1149/1.1344528.

[53] D.G. ALTENPOHL, Use of Boehmite Films For Corrosion Protection of Aluminum, Corrosion 18 (1962) 143t-153t. doi:10.5006/0010-9312-18.4.143.

[54] R.U. Din, V.C. Gudla, M.S. Jellesen, R. Ambat, Accelerated growth of oxide film on aluminium alloys under steam: Part I: Effects of alloy chemistry and steam vapour pressure on microstructure, Surf. Coatings Technol. 276 (2015) 77-88.

[55] R.U. Din, M.S. Jellesen, R. Ambat, Performance Comparison of Steam-Based and Chromate Conversion Coatings on Aluminum Alloy 6060, Corrosion. 71 (2015) 839-853. doi:10.5006/1624.

[56] R. Ud Din, M.S. Jellesen, R. Ambat, Role of acidic chemistries in steam treatment of aluminium alloys, Corros. Sci. 99 (2015) 258-271. doi:10.1016/j.corsci.2015.07.018.

[57] R.U. Din, S. Yuksel, M.S. Jellesen, P. Møller, R. Ambat, Steam Assisted Accelerated Growth of Oxide Layer on Aluminium Alloys, In: Proceedings of Eurocorr 2013 European Federation of Corrosion (2013).

[58] R.U. Din, N. Nikogeorgos, M.S. Jellesen, R. Shabadi, R. Ambat, Influence of steam-based pretreatment using acidic chemistries on the adhesion performance of powder coated aluminium alloy AA6060, Int. J. Adhes. Adhes. 74 (2017) 167-176. doi:10.1016/j.ijadhadh.2017.01.008.

[59] M. Jariyaboon, P. Møller, R. Ambat, Effect of pressurized steam on AA1050 aluminium, AntiCorrosion Methods Mater. 59 (2012) 103-109. doi:10.1108/00035591211224645.

[60] F. Eckermann, T. Suter, P.J. Uggowitzer, A. Afseth, P. Schmutz, The influence of MgSi particle reactivity and dissolution processes on corrosion in Al-Mg-Si alloys, Electrochim. Acta. 54 (2008) 844-855.

[61] P.G. Sheasby, R. Pinner, The surface treatment and finishing of aluminum and its alloys, ASM international, 2001.

[62] W. Vedder, D.A. Vermilyea, Aluminum + water reaction, Trans. Faraday Soc. 65 (1969) 561. doi:10.1039/tf9696500561.

[63] P. Leblanc, G.S. Frankel, A study of corrosion and pitting initiation of AA2024-T3 using atomic force microscopy, J. Electrochem. Soc. 149 (2002) B239-B247. doi:10.1149/1.1471546. 
[64] N. Birbilis, R.G. Buchheit, Electrochemical characteristics of intermetallic phases in aluminum alloys : An experimental survey and discussion, J. Electrochem. Soc. 152 (2005) B140-B151. doi:10.1149/1.1869984.

[65] J.S. Chen, T. Zhu, C.M. Li, X.W. Lou, Building Hematite Nanostructures by Oriented Attachment, Angew. Chemie Int. Ed. 50 (2011) 650-653. doi:10.1002/anie.201005365.

[66] E.J.H. Lee, C. Ribeiro, E. Longo, E.R. Leite, Oriented Attachment: An Effective Mechanism in the Formation of Anisotropic Nanocrystals, J. Phys. Chem. B. 109 (2005) 20842-20846. doi:10.1021/jp0532115.

[67] P.A. van Aken, B. Liebscher, Quantification of ferrous/ferric ratios in minerals: new evaluation schemes of Fe L 23 electron energy-loss near-edge spectra, Phys. Chem. Miner. 29 (2002) 188200. doi:10.1007/s00269-001-0222-6.

[68] K.A. Yasakau, M.L. Zheludkevich, S. V Lamaka, M.G.S. Ferreira, Role of intermetallic phases in localized corrosion of AA5083, Electrochim. Acta. 52 (2007) 7651-7659.

[69] A.K. Mukhopadhyay, A.K. Sharma, Influence of Fe-bearing particles and nature of electrolyte on the hard anodizing behaviour of AA 7075 extrusion products, Surf. Coatings Technol. 92 (1997) 212-220.

[70] M. Jariyaboon, P. Møller, R.E. Dunin-Borkowski, R. Ambat, FIB-SEM investigation of trapped intermetallic particles in anodic oxide films on AA1050 aluminium, Anti-Corrosion Methods Mater. 58 (2011) 173-178. doi:10.1108/00035591111148885.

[71] L.E. Fratila-Apachitei, F.D. Tichelaar, G.E. Thompson, H. Terryn, P. Skeldon, J. Duszczyk, L. Katgerman, A transmission electron microscopy study of hard anodic oxide layers on $\mathrm{AlSi}(\mathrm{Cu})$ alloys, Electrochim. Acta. 49 (2004) 3169-3177.

[72] C. Colliex, T. Manoubi, C. Ortiz, Electron-energy-loss-spectroscopy near-edge fine structures in the iron-oxygen system, Phys. Rev. B. 44 (1991) 11402-11411.

doi:10.1103/PhysRevB.44.11402.

[73] J. Jasinski, K.E. Pinkerton, I.M. Kennedy, V.J. Leppert, Spatially resolved energy electron loss spectroscopy studies of iron oxide nanoparticles, Microsc. Microanal. 12 (2006) 424-431. doi:10.1017/S1431927606060491.

[74] J. Bischoff, A.T. Motta, EFTEM and EELS analysis of the oxide layer formed on HCM12A exposed to SCW, J. Nucl. Mater. 430 (2012) 171-180. doi:10.1016/j.jnucmat.2012.06.017.

[75] Y. Kihn, G.E. Thompson, G. Galaup, P. Skeldon, X. Zhou, K. Shimizu, H. Habazaki, Morphology, composition and structure of anodic films on Al-Cr alloys, Corros. Sci. 42 (2000) 533-544. doi:10.1016/S0010-938X(99)00063-3. 
Table 1 Chemical composition of alloys in wt. \% (Remaining percentage Al), measured by GDOES.

\begin{tabular}{ccccccccc}
\hline Alloy & Si & Fe & Cu & Mn & Mg & Cr & Zn & Ti \\
\hline AA3102 & 0.40 & 0.70 & 0.10 & 0.40 & - & 0.10 & 0.30 & 0.10 \\
\hline AA9108 & 0.20 & 0.30 & 0.20 & 1.00 & 0.05 & 0.10 & 0.20 & 0.15 \\
\hline
\end{tabular}


Table 2 EDS analysis in wt. \% of AA3102 and AA9108 alloy surface before and after steam treatment.

\begin{tabular}{|c|c|c|c|c|c|c|c|}
\hline Alloy & Area & Treatment & $\mathbf{O}$ & Al & $\mathbf{S i}$ & Mn & $\mathrm{Fe}$ \\
\hline \multirow{2}{*}{ AA3102 } & \multirow{2}{*}{ Al matrix } & As received & - & 100 & - & - & - \\
\hline & & Steam treated & $29.2 \pm 2.0$ & $70.8 \pm 3.0$ & - & - & - \\
\hline \multirow{2}{*}{ AA3102 } & \multirow{2}{*}{ Intermetallic particle } & As received & - & $81.0 \pm 2.0$ & $2.6 \pm 0.5$ & $9.7 \pm 1.0$ & $6.8 \pm 2.3$ \\
\hline & & Steam treated & $42.3 \pm 2.0$ & $53.9 \pm 3.0$ & $0.5 \pm 0.2$ & $1.7 \pm 0.5$ & $1.5 \pm 0.3$ \\
\hline \multirow{2}{*}{ AA9108 } & \multirow{2}{*}{ Al matrix } & As received & - & 100 & - & - & - \\
\hline & & Steam treated & $27.8 \pm 1.2$ & $72.2 \pm 2.0$ & - & - & - \\
\hline \multirow{2}{*}{ AA9108 } & \multirow{2}{*}{ Intermetallic particle } & As received & - & $86.5 \pm 2.0$ & $1.4 \pm 0.5$ & $3.3 \pm 0.5$ & $8.9 \pm 1.2$ \\
\hline & & Steam treated & $42.1 \pm 2.0$ & $46.2 \pm 2.0$ & $0.6 \pm 0.2$ & $1.5 \pm 0.4$ & $9.6 \pm 2.8$ \\
\hline
\end{tabular}


Table 3 EDS analysis in wt.\% of different areas marked in Figure 3.

\begin{tabular}{ccccccc}
\hline Figure & Area & O & Al & Si & Mn & Fe \\
\hline \multirow{2}{*}{3 (b) } & 1 & 35.9 & 45.1 & 1.0 & 10.1 & 7.6 \\
\cline { 2 - 7 } & 2 & 41.6 & 56.7 & - & 1.8 & - \\
\hline \multirow{2}{*}{$3(d)$} & 3 & 30.9 & 51.2 & 1.3 & 8.4 & 8.2 \\
\cline { 2 - 6 } & 4 & 48.1 & 50.0 & 0.5 & 1.3 & - \\
\hline
\end{tabular}



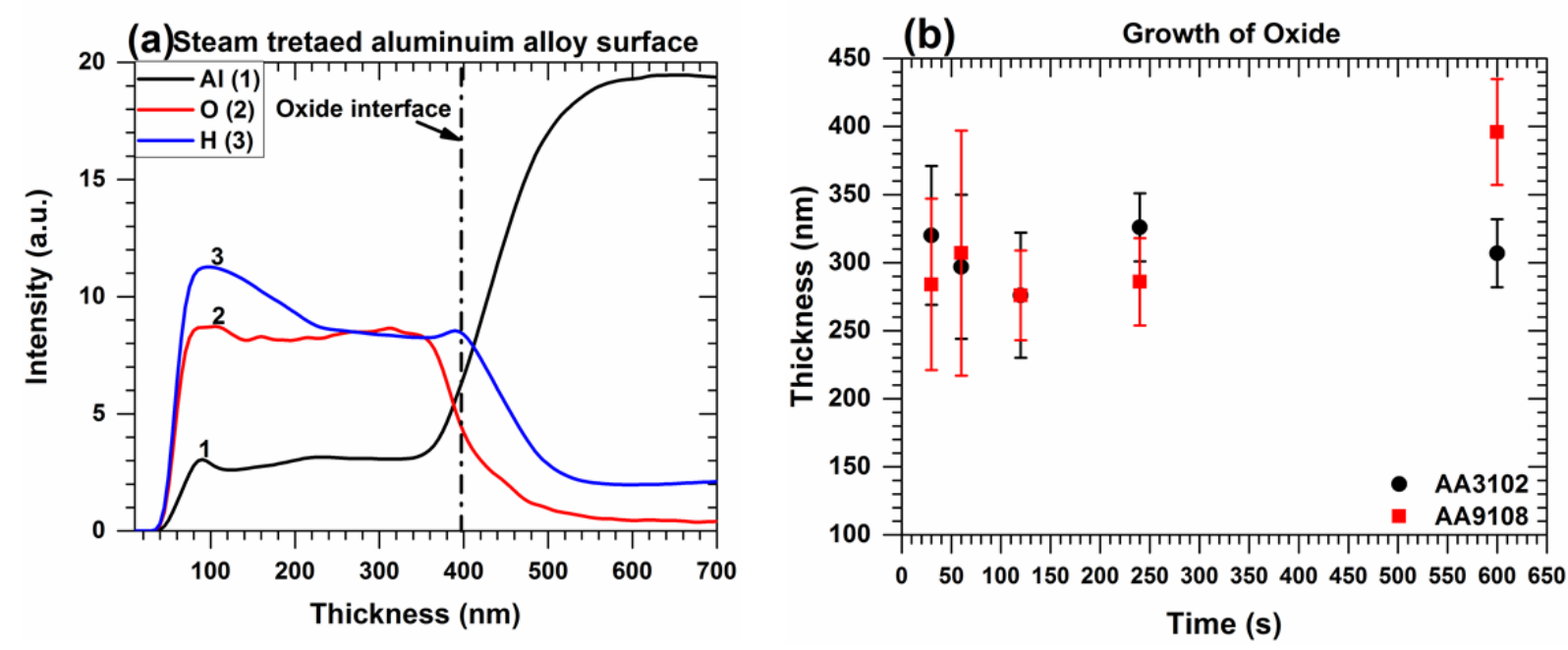

Figure 1 Relative chemical compositional profile of steam treated aluminium alloy surface acquired using RF-GDOES: (a) AA9108 surface after $10 \mathrm{~min}$ and (b) the average thickness of the oxide layer on AA3102 and AA9108 surfaces after various steam treatment times. 


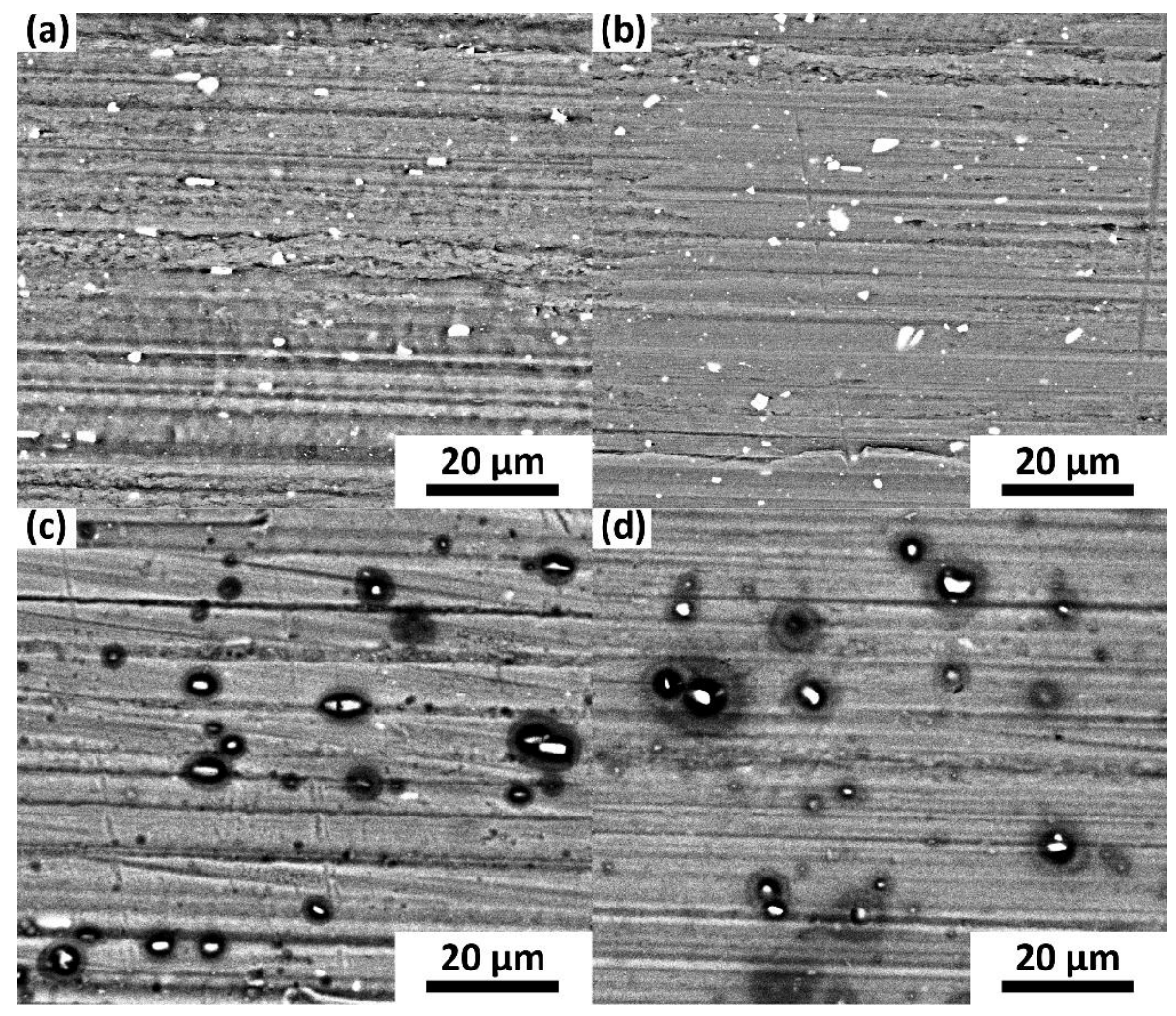

Figure 2 Backscattered electron SEM images of the surface of the aluminium alloys as received conditions, (a) AA3102 and (b) AA9108. (c) and (d) show after steam treatment for $600 \mathrm{~s}$ to AA3102 and AA9108, respectively. 

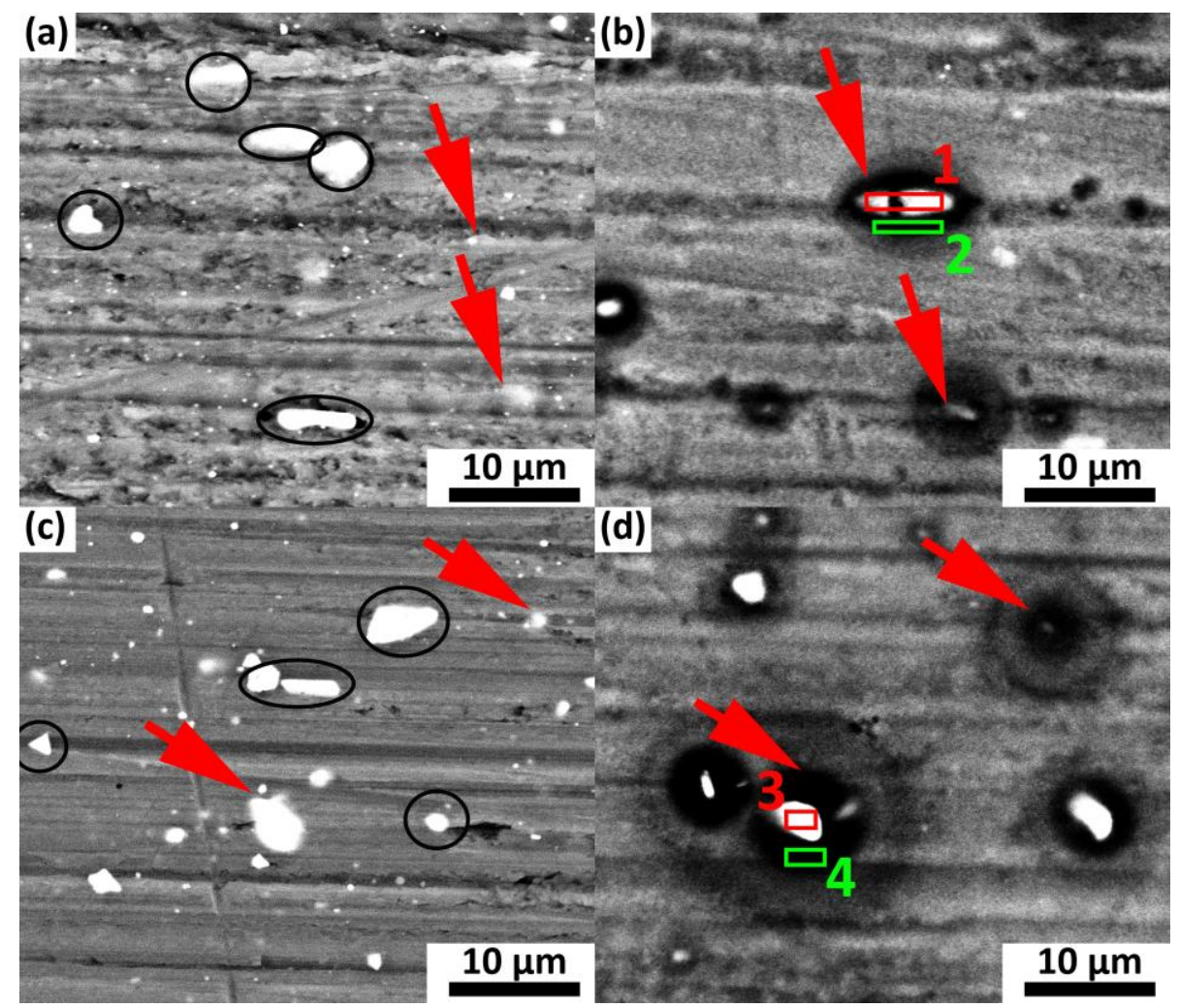

Figure 3 Backscattered SEM images of different marked areas on aluminium alloys before: (a) AA3102 (c) AA9108; and after steam treatment (b) AA3102 (d) AA9108 for $600 \mathrm{~s}$, subsequently. The intermetallic particles marked by arrows show change in microstructure of same intermetallic particles before and after steam treatment, while circles represents the dislodged intermetallic particles. 


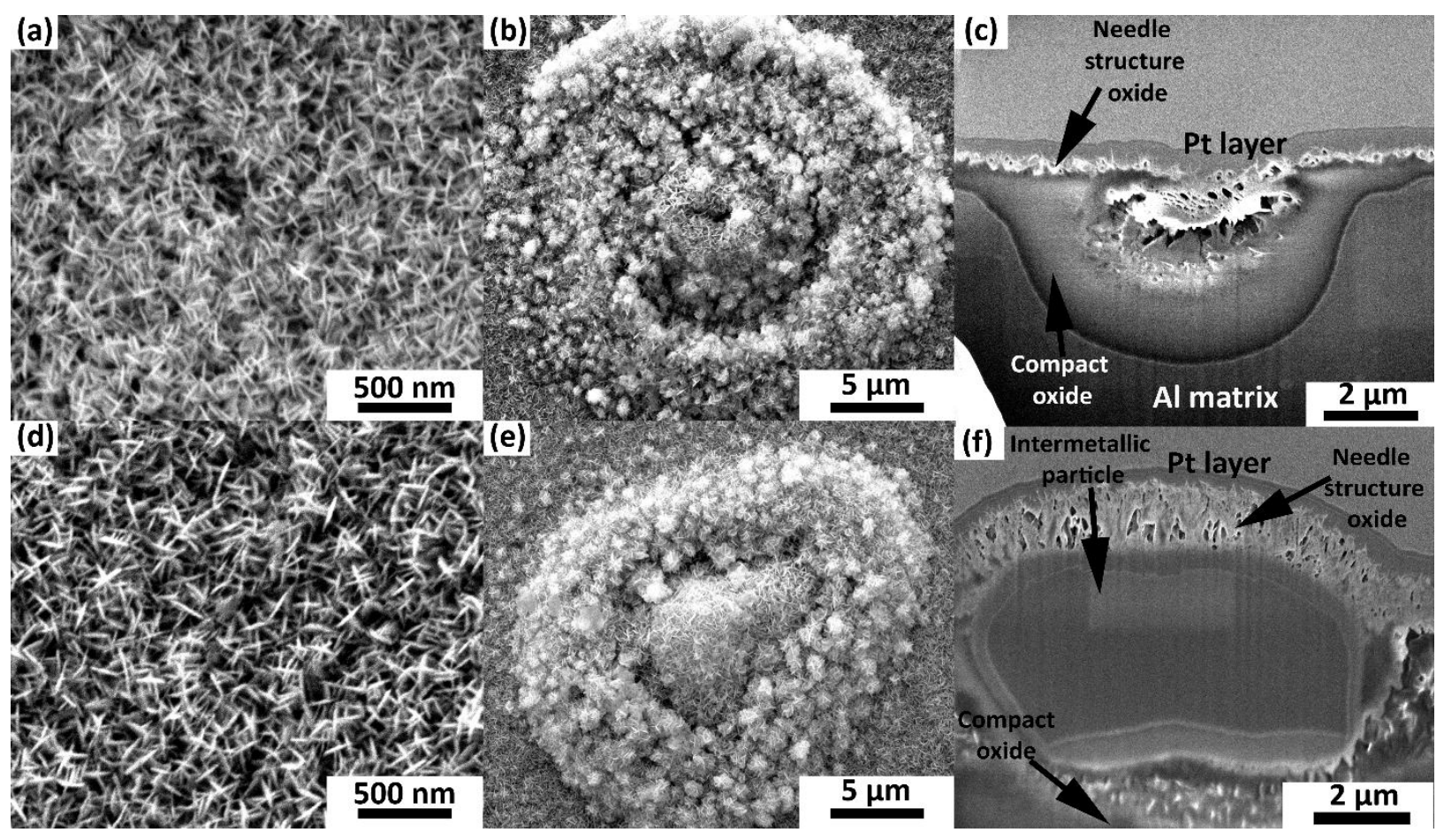

Figure 4 Secondary electron SEM images of aluminium matrix on (a) AA3102 and (d) AA9108 and coverage of intermetallic particles on (b) AA3102 and (e) AA9108 after steam treatment of 600 s. (c) and (f) represent the FIB cross sections of the intermetallic particles presented in (b) and (e), respectively. 


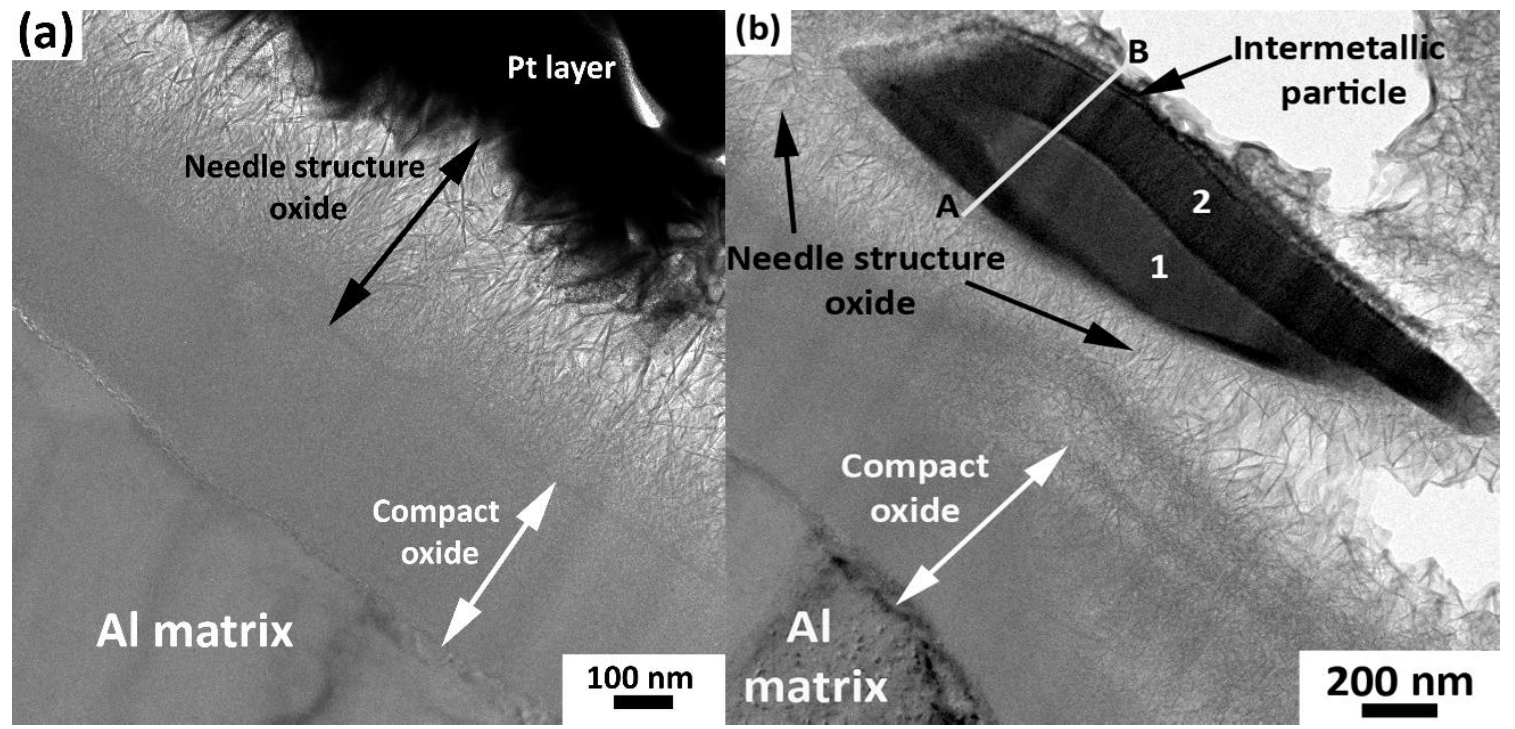

Figure 5 Bright field TEM images showing cross-section of (a) steam generated oxide layer (b) coverage of Al-Fe-Si intermetallic particle after $600 \mathrm{~s}$ of steam treatment. 


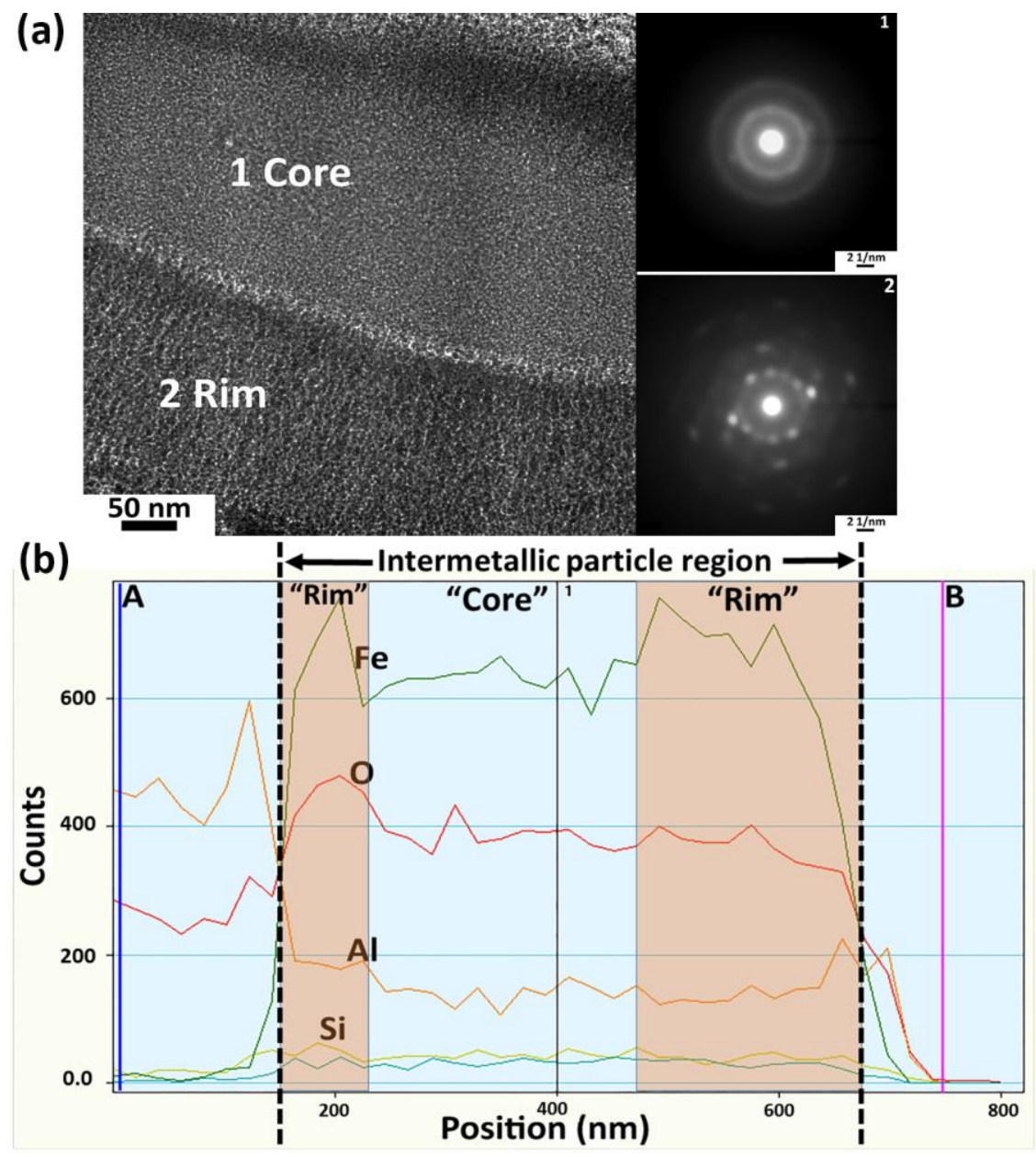

Figure 6 (a) Electron diffraction patterns from corresponding areas of regions 1 (core) and 2 (rim) which are also marked in Figure 5 (b) and (b) shows the EDS line profile from point A to B as marked in Figure 5 (b). 

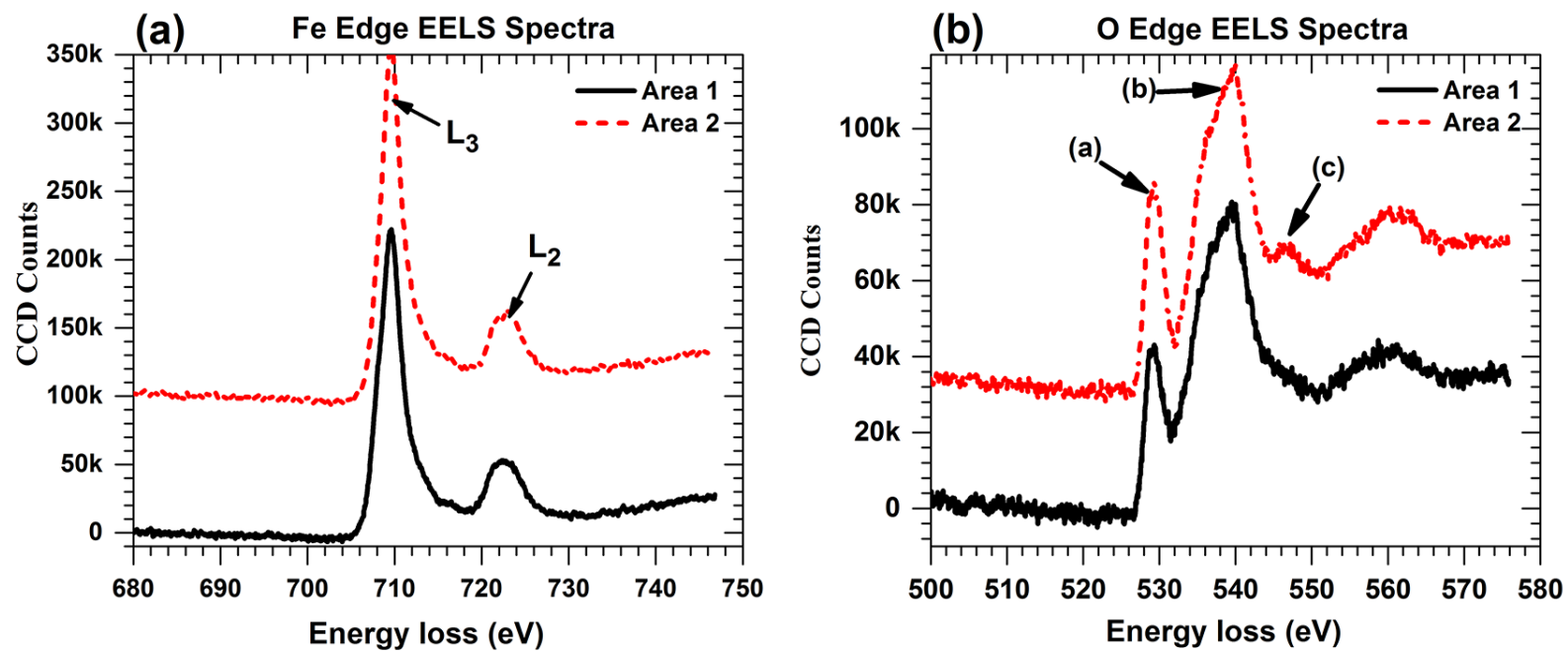

Figure 7 EELS spectra of the $\mathrm{Fe}_{2,3}$ edge and oxygen $\mathrm{K}$ edge acquired from regions 1 and 2 marked in Figure 6 (b). 